\title{
Cannabidiol causes activated hepatic stellate cell death through a mechanism of endoplasmic reticulum stress-induced apoptosis
}

\author{
MP Lim ${ }^{1}$, LA Devi ${ }^{*, 1}$ and R Rozenfeld ${ }^{\star, 1,2}$
}

The major cellular event in the development and progression of liver fibrosis is the activation of hepatic stellate cells (HSCs). Activated HSCs proliferate and produce excess collagen, leading to accumulation of scar matrix and fibrotic liver. As such, the induction of activated HSC death has been proposed as a means to achieve resolution of liver fibrosis. Here we demonstrate that cannabidiol (CBD), a major non-psychoactive component of the plant Cannabis sativa, induces apoptosis in activated HSCs through a cannabinoid receptor-independent mechanism. CBD elicits an endoplasmic reticulum (ER) stress response, characterized by changes in ER morphology and the initiation of RNA-dependent protein kinase-like ER kinase-, activating transcription factor-6-, and inositol-requiring ER-to-nucleus signal kinase-1 (IRE1)-mediated signaling cascades. Furthermore, CBD induces downstream activation of the pro-apoptotic IRE1/ASK1/C-Jun N-terminal kinase pathway, leading to HSC death. Importantly, we show that this mechanism of CBD-induced ER stress-mediated apoptosis is specific to activated HSCs, as it occurs in activated human and rat HSC lines, and in primary in vivo-activated mouse HSCs, but not in quiescent HSCs or primary hepatocytes from rat. Finally, we provide evidence that the elevated basal level of ER stress in activated HSCs has a role in their susceptibility to the pro-apoptotic effect of CBD. We propose that CBD, by selectively inducing death of activated HSCs, represents a potential therapeutic agent for the treatment of liver fibrosis.

Cell Death and Disease (2011) 2, e170; doi:10.1038/cddis.2011.52; published online 9 June 2011

Subject Category: Experimental Medicine

Liver fibrosis is the tenth leading cause of death in the US, affecting over 400000 patients. ${ }^{1}$ As the common woundhealing response to liver injury, it is the outcome of many chronic liver diseases, including viral and autoimmune hepatitis, alcoholic liver disease, and obesity-related liver disease. ${ }^{2}$ Because of the high incidence of cirrhosis and liver failure that results from fibrosis, identifying pharmacological treatments that can halt the progression of, or even reverse, fibrosis is of utmost clinical importance. The activation of hepatic stellate cells (HSCs) in response to liver injury is considered a key cellular event underlying hepatic fibrogenesis. HSC activation refers to the transdifferentiation of quiescent HSCs into proliferative and contractile myofibroblast-like cells. These activated HSCs secrete excess extracellular matrix (ECM) proteins, predominantly collagen type I, leading to the accumulation of scar matrix, and ultimately hepatic fibrosis. ${ }^{3}$ As HSCs have a critical role in fibrogenesis, the elimination of activated HSCs through cell death has been proposed as a mechanism to attenuate or reverse liver fibrosis. ${ }^{4}$ Therefore, much research has been aimed at identifying compounds that target activated HSCs and lead to HSC death.

Recent studies have investigated the effects of cannabinoids in liver disease, highlighting a role for the endocannabinoid system (reviewed in Tam et al. ${ }^{5}$ ) The endogenous cannabinoid ligand anandamide (AEA), a type I/type II cannabinoid receptor $\left(\mathrm{CB}_{1} \mathrm{R} / \mathrm{CB}_{2} \mathrm{R}\right)$ agonist, has been shown to induce necrosis in activated HSCs, albeit at high concentrations ranging from $25 \mu \mathrm{M}$ to $100 \mu \mathrm{M} .{ }^{6}$ However, because $C_{1} R$ is highly expressed in the central nervous system, the prospective use of AEA as an effective therapeutic agent is diminished by its potential to cause adverse effects at such high concentrations. Thus, the identification of alternative cannabinoids that effectively induce HSC death at lower concentrations, while exhibiting little or no receptor activity, may offer more appealing drug candidates.

Cannabidiol (CBD) is the major non-psychoactive plantderived cannabinoid. In recent years, CBD has been shown to act in vivo as an anti-inflammatory molecule $e^{7,8}$ as an

\footnotetext{
${ }^{1}$ Department of Pharmacology and Systems Therapeutics, Mount Sinai School of Medicine, New York, NY 10029, USA and ${ }^{2}$ Alcoholic Liver Disease Research Center, Mount Sinai School of Medicine, New York, NY 10029, USA

${ }^{*}$ Corresponding authors: R Rozenfeld or LA Devi, Department of Pharmacology and Systems Therapeutics, Mount Sinai School of Medicine, 19-86 Annenberg Building, One Gustave L. Levy Place, New York, NY 10029, USA. Tel: (212) 241-6545; Fax: (212) 996-7214; E-mail: raphael.rozenfeld@ mssm.edu or lakshmi.devi@ mssm.edu Keywords: liver fibrosis; cannabinoid; cannabis; unfolded protein response; antifibrogenic

Abbreviations: 2-AG, 2-arachydonoyl glycerol; AEA, anandamide; ASK1, apoptosis signal-regulating kinase 1; $\alpha$ SMA, alpha smooth muscle actin; ATF4, activating transcription factor 4; ATF6, activating transcription factor $6 ; \mathrm{CB}_{1} \mathrm{R}$, type I cannabinoid receptor; $\mathrm{CB}_{2} \mathrm{R}$, type II cannabinoid receptor; $\mathrm{CBD}$, cannabidiol; $\mathrm{DN}$, dominant negative; ECM, extracellular matrix; elF2 $\alpha$, eukaryotic translation initiation factor $2 \alpha$; ER, endoplasmic reticulum; CHOP, C/EBP (CCAAT/enhancer-binding protein) homologous protein; GAPDH, glyceraldehyde 3-phosphate dehydrogenase; GRP78, glucose-regulated protein $78 \mathrm{kDa}$; HSC, hepatic stellate cell; IRE1 $\alpha$, inositolrequiring ER-to-nucleus signal kinase-1 $\alpha$; JNK, c-Jun N-terminal kinase; PARP, poly-(ADP ribose) polymerase; PERK, PRKR (RNA-dependent protein kinase)-like ER kinase; UPR, unfolded protein response; XBP-1, X-box-binding protein-1

Received 22.11.10; revised 25.4.11; accepted 06.5.11; Edited by M Piacentini
} 
antioxidant, ${ }^{9}$ and importantly, as an anti-proliferative compound inducing a loss in viability in a number of tumor cell lines. ${ }^{10-12}$ Given the anti-proliferative properties of CBD, we hypothesized that this compound could exhibit therapeutic potential in the context of liver fibrosis by preventing proliferation of activated HSCs. Here, we find that CBD induces apoptosis in activated HSCs, and we identify endoplasmic reticulum (ER) stress as the molecular mechanism underlying this process.

\section{Results}

CBD induces activated HSC apoptosis in a cannabinoid receptor-independent manner. To investigate the potential of CBD and other cannabinoid ligands to induce activated HSC death, we treated cultured activated HSCs, isolated from livers of rats that were fed an 8-month ethanol diet ${ }^{13}$ (see details in Materials and Methods), with increasing concentrations of different cannabinoids for $8 \mathrm{~h}$, and measured cell viability using an acid phosphatase assay. Incubation of cells with up to $10 \mu \mathrm{M}$ of either $\mathrm{AM} 630\left(\mathrm{CB}_{2} \mathrm{R}\right.$ antagonist), JWH133 ( $\mathrm{CB}_{2} \mathrm{R}$ agonist), PF514273 $\left(\mathrm{CB}_{1} \mathrm{R}\right.$ antagonist), AM251 (CB $\mathrm{R}$ antagonist), or $\mathrm{ACEA}\left(\mathrm{CB}_{1} \mathrm{R}\right.$ agonist) had little or no effect, whereas $5 \mu \mathrm{M}$ of either $\mathrm{CBD}$ or CP55940 ( $\mathrm{CB}_{1} \mathrm{R} / \mathrm{CB}_{2} \mathrm{R}$ agonist) was sufficient to cause $\sim 60 \%$ and $90 \%$ loss of viability, respectively. In contrast to exogenous ligands, $20 \mu \mathrm{M}$ AEA (endogenous $C_{1} R / C_{2} R$ agonist) was required to achieve a similar effect, whereas 2-arachydonoyl glycerol (2-AG, endogenous $C B_{1} R / C_{2} R$ agonist) treatment resulted in no significant change in the survival of these cells (Figure 1a).

In parallel, we investigated the ability of these cannabinoids to kill activated HSCs by examining the presence of cleaved poly-(ADP ribose)-polymerase (PARP), a marker for cell death, following $5 \mu \mathrm{M}$ treatment of cells. Among these compounds, only AEA and CBD were able to promote activated HSC death, as indicated by western blot analysis of PARP cleavage (Figure 1b), in agreement with the results obtained with the cell viability assay. Upon further examination, we found that CBD induced activated HSC death in a dose- and time-dependent manner, detectable after $6 \mathrm{~h}$ with $5 \mu \mathrm{M}$ treatment (Figure 1c). We then confirmed the induction of apoptosis by CBD using flow cytometric analysis of FITCAnnexin $V$ staining (Figure 1d).

In order to characterize the mechanism through which CBD causes apoptosis, we first investigated whether $C B D$ was acting through cannabinoid receptors $C_{1} R$ or $C B_{2} R$. We found that blocking $\mathrm{CB}_{1} \mathrm{R}$ or $\mathrm{CB}_{2} \mathrm{R}$ had no effect on CBDinduced PARP cleavage (Figure 2a) and activated HSC viability (Figure $2 b$ ), in contrast to the death induced by CP55940, which appears to be mediated at least, in part, by $\mathrm{CB}_{2} \mathrm{R}$. Co-treatment with the $\mathrm{CB}_{2} \mathrm{R}$ antagonist $\mathrm{AM} 630$ decreased CP55940-induced cell death by over 50\% (data not shown). These results support a cannabinoid receptorindependent mechanism for CBD-induced apoptosis.

CBD causes a change in morphology of the ER in activated HSCs through induction of ER stress. During the course of our experiments, we noticed marked changes in the morphology of CBD-treated activated HSCs. The presence of distinct structures surrounding the nucleus suggested an effect of CBD on the ER (Figure 2c). This was supported by an alteration in the distribution and localization of the ER chaperone calnexin, with the disappearance of uniform network-like ER structure and the formation of perinuclear vacuole-like structures (Figure 2d). This was further confirmed by electron microscopy showing that CBD treatment caused ER dilation (Figure 2e). These changes in ER morphology suggested that CBD induces ER stress.

We further investigated the effect of CBD on the ER in the activated HSCs by examining changes in the expression of calnexin, as well as the transcription factor C/EBP (CCAAT/ enhancer-binding protein) homologous protein (CHOP), a major marker of prolonged ER stress. Western blot analysis showed that CBD treatment led to increased expression of both calnexin and CHOP (Figure 2f). Furthermore, upregulation of $\mathrm{CHOP}$, an important potentiator of pro-apoptotic signaling following ER stress, provided evidence that ER stress may mediate CBD-induced apoptosis of activated HSCs.

CBD promotes apoptosis and ER stress in activated HSCs, but not in control HSCs or primary hepatocytes. In order to assess the specificity of CBDinduced apoptosis and ER stress, we examined the effect of CBD on the expression of PARP, calnexin, and CHOP in different cell lines, as well as in primary cells. We first compared HSCs from ethanol-treated rats with HSCs from control rats. ${ }^{13}$ HSCs from control rats exhibit a markedly lower activation state as compared with HSCs from ethanoltreated rats, indicated by 20 -fold lower expression of alpha smooth muscle actin ( $\alpha \mathrm{SMA}$; see Figure $3 \mathrm{a}$, inset). Upon comparing the effect of treatment with $5 \mu \mathrm{M}$ CBD in these cells, we found that CBD did not alter PARP, calnexin, and CHOP expression in control HSCs, suggesting that the proapoptotic and ER stress effects of CBD were specific to the activated HSC phenotype (Figure $3 a$ ).

In primary in vivo-activated mouse HSCs and in LX-2 cells (immortalized human HSC line derived from cirrhotic patient ${ }^{14}$ ), CBD led to PARP cleavage, upregulation of calnexin, and induction of $\mathrm{CHOP}$ expression, consistent with what we observed in activated HSCs from rats (Figures $3 b$ and $c$ ). In contrast, CBD treatment did not induce PARP cleavage or upregulation of calnexin and $\mathrm{CHOP}$ in primary rat hepatocytes (Figure $3 d$ ), confirming the specificity of the pro-apoptotic effect of CBD to activated HSCs.

To further examine the effect of CBD across different cell types, we compared the viability of HSCs from control rats, HSCs from ethanol-treated rats, and primary rat hepatocytes under $0-20 \mu \mathrm{M}$ range of CBD treatment. As shown before, $5 \mu \mathrm{M}$ CBD was sufficient to cause $\sim 60 \%$ decrease in viability of HSCs from ethanol-treated rats, but not in HSCs from control rats, for which $10 \mu \mathrm{M}$ CBD was required to induce a significant loss that occurs to an even lesser extent ( $40 \%$ reduction). In contrast to HSCs, primary rat hepatocytes maintained maximal viability under treatment with up to $20 \mu \mathrm{M}$ CBD (Figure 3e). Altogether, these findings suggest that CBD, in a dose-dependent manner, specifically targets activated HSCs to cause death. 
a
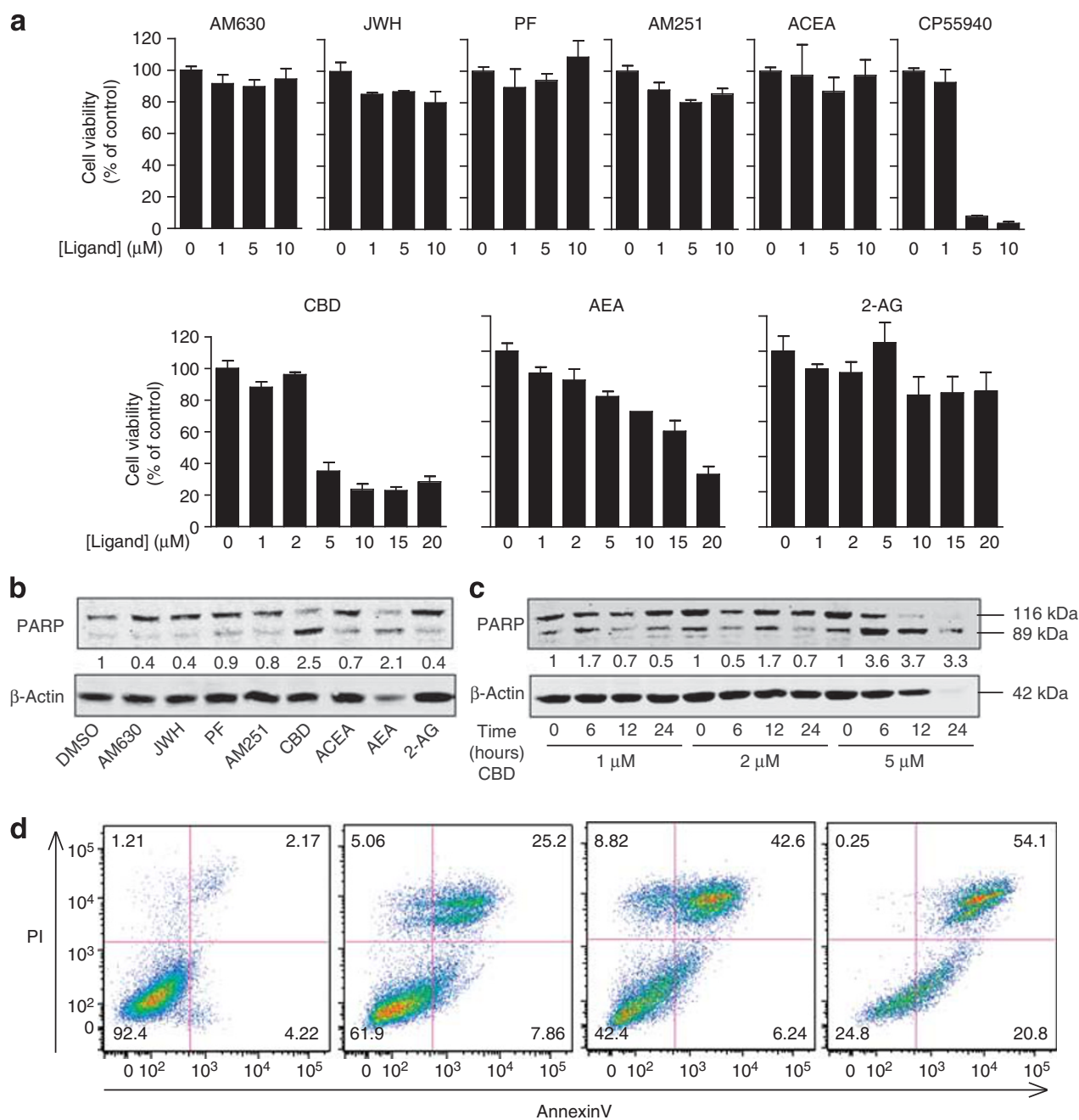

Figure 1 CBD induces apoptosis in activated HSCs. (a) Cell viability of activated rat HSCs was determined using an acid phosphatase assay following serum starvation and 8-h treatment with indicated concentrations of cannabinoid ligands. Cell survival is presented as percent of acid phosphatase activity in vehicle-treated cells, expressed as mean \pm S.E.M. of triplicate experiments. $A_{M} 630, C B_{2} R$ antagonist; JWH (JWH133), $C_{2} R$ agonist; $P F$ (PF514273), $C_{1} R$ antagonist; $A M 251, C_{1} R$ antagonist; $A C E A, C B_{1} R$ agonist; $C P 55940, C B_{1} R / C B_{2} R$ agonist; $A E A$, endogenous $C B_{1} R / C_{2} R$ agonist; 2-AG, endogenous $C B_{1} R / C B_{2} R$ agonist. (b) Cell death was determined by western blot analysis of cleaved PARP in activated-rat HSCs, following 12-h incubation in serum-free media in the presence of either vehicle (DMSO) or $5 \mu \mathrm{M}$ of indicated cannabinoid ligands. PARP cleavage is expressed as cleaved PARP over total PARP. (c) PARP cleavage was examined as in (b) in activated rat HSCs treated with CBD for the indicated concentrations and time periods. Western blots are representative of $n=$ three experiments. (d) Activated rat HSCs were incubated in serum-free media in the absence or presence of $5 \mu \mathrm{M} \mathrm{CBD}$ for 2, 4, and $8 \mathrm{~h}$, then stained for FITC-Annexin V and propidium iodide (PI). Cells were sorted and analyzed by flow cytometry. The percentage of cells that are either negative or positive for Annexin $\mathrm{V}$ and/or PI is indicated in the appropriate quadrant of each panel

CBD induces PERK-, ATF6-, and IRE1-mediated ER stress response in activated HSCs. We further investigated the mechanism for CBD-induced ER stress and apoptosis by characterizing the CBD-induced changes in the major mediators of ER stress signaling as described below. Cells respond to ER stress through a protective mechanism termed the unfolded protein response (UPR) in order to restore normal ER function. Upon stressful stimulus, this adaptive response is initiated by the repression release of three ER transmembrane proteins - PRKR (RNAdependent protein kinase)-like ER kinase (PERK), ATF6, and inositol-requiring ER-to-nucleus signal kinase-1 (IRE1) from the ER chaperone glucose-regulated protein $78 \mathrm{kDa}$
(GRP78). The subsequent activation of these ER stress sensors initiates a cascade of signaling events that result in the expression of genes that are critical for overcoming ER stress, including transcription factors and molecular chaperones $^{15,16}$ (Figure 4a).

Release of PERK from GRP78 allows PERK activation through receptor autophosphorylation. Activated PERK can phosphorylate and inhibit eukaryotic translation initiation factor $2 \alpha$ (elF $2 \alpha$ ), potentiating the elF $2 \alpha$-independent translation and nuclear translocation of activating transcription factor (ATF)-4 to induce gene expression of chaperones and transcription factors such as CHOP. In activated HSCs, we found that CBD induced phosphorylation of PERK at $2 \mathrm{~h}$, 

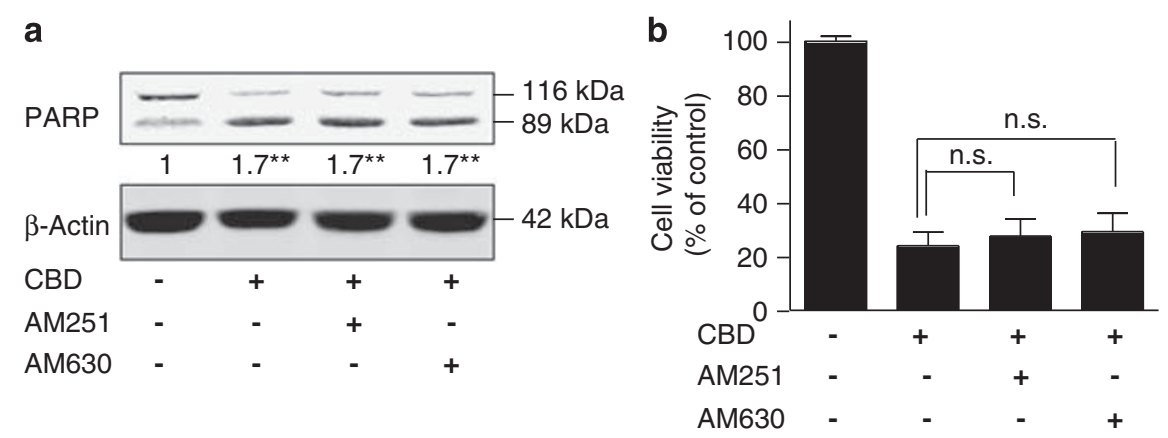

c
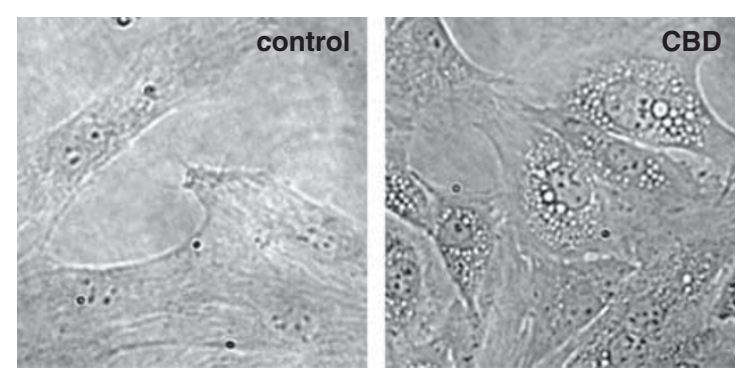

d

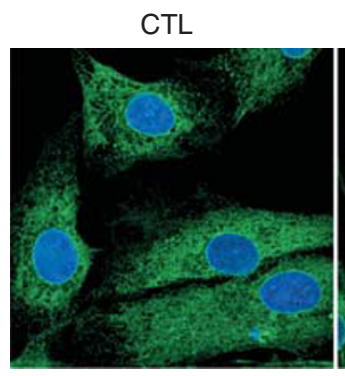

4 hours

8 hours
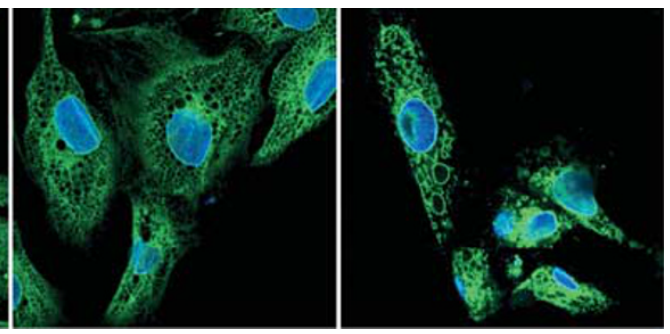

e

CTL

CBD
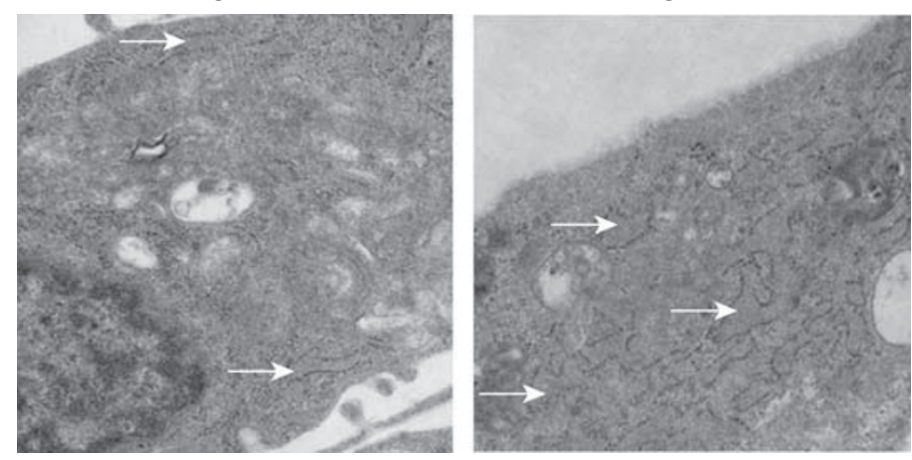

f

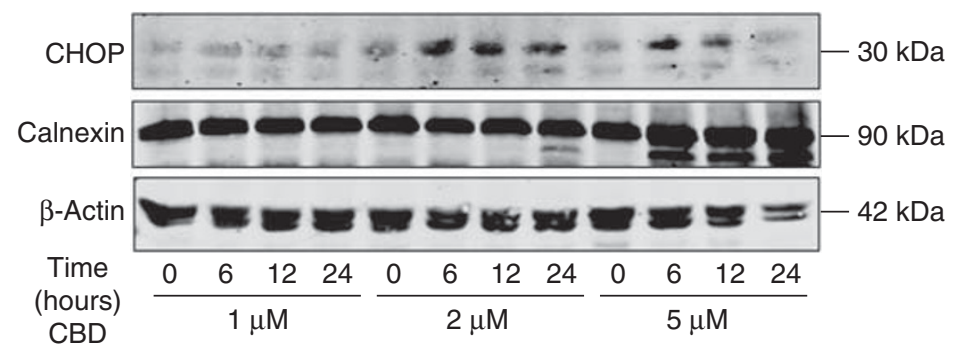


followed by phosphorylation of elF $2 \alpha$ at $4 \mathrm{~h}$ (Figure $4 \mathrm{~b}$ ). In line with this, we also detected a time-dependent accumulation of ATF4 in the nucleus (Figure 4c).

Upon release from GRP78, ATF6 is cleaved and translocated to the nucleus to induce CHOP and X-box-binding protein-1 (XBP1) expression. Western blot analysis showed that CBD induced accumulation of cleaved ATF6 $\alpha$ in the nucleus (Figure 4c), indicating activation of the ATF6mediated ER stress response.

Release of IRE1 from GRP78 during the UPR is followed by IRE1 autophosphorylation and phospho-IRE1-mediated excision of a 26-nucleotide intron from XBP1 mRNA, facilitating nuclear translocation of spliced XBP1 (XBP1s) protein and induction of expression of genes such as P58 ${ }^{\text {IPK } .{ }^{17}}$ CBD treatment of activated HSCs led to an increase in phosphorylated IRE1, accompanied by slight induction of $P 58^{I P K}$ expression (Figure $4 b$ ). We also found that CBD induced splicing of XBP1 mRNA in a time- and dosedependent manner (Figure 4d). Moreover, a sharp increase in nuclear XBP1s protein was detected from $2-8 \mathrm{~h}$ of treatment (Figure 4c), supporting CBD-induced activation of the IRE1-mediated ER stress-signaling cascade. a

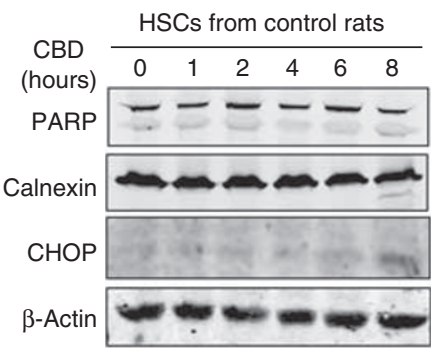

b

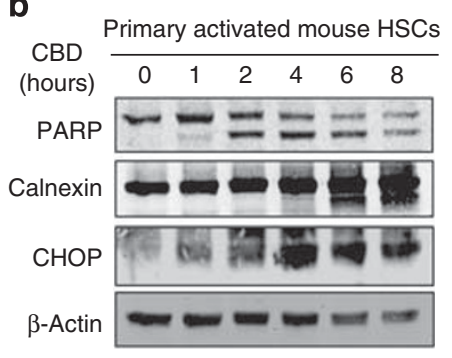

e

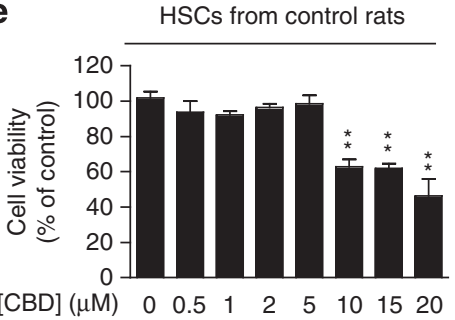

C
HSCs from ethanol-treated rats
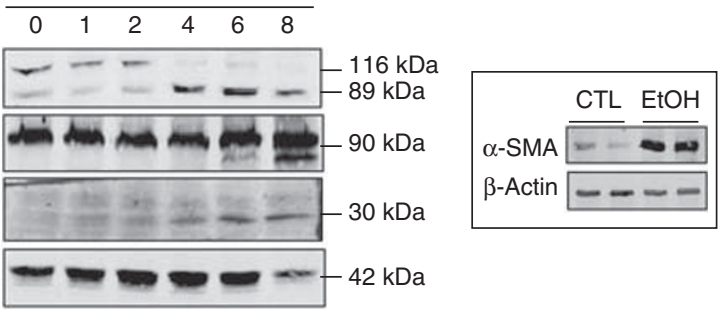
Human HSCs LX-2

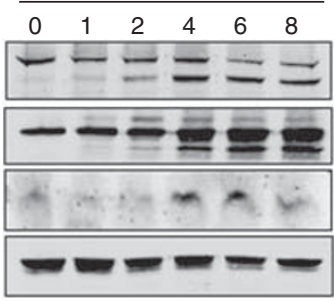

d Primary rat hepatocytes
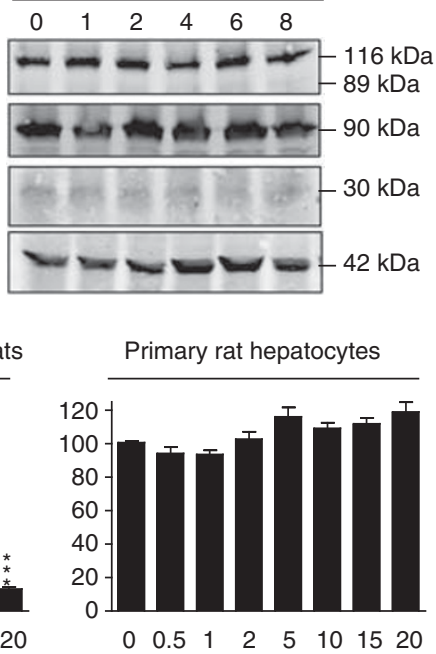

Figure 3 Pro-apoptotic effect of CBD is specific to activated HSCs. (a) HSCs from control or ethanol-fed rats, (b) primary mouse in vivo-activated HSCs, (c) LX-2 cells (human HSC line derived from cirrhotic patient), and (d) primary rat hepatocytes were incubated in serum-free media with $5 \mu \mathrm{M} \mathrm{CBD}$ for $0-8 \mathrm{~h}$. Cell lysates were subjected to western blot analysis and probed for PARP, calnexin, and CHOP to detect cell death and ER stress. (e) Acid phosphatase activity was measured in order to determine cell viability following treatment with indicated concentrations of CBD for $8 \mathrm{~h}$ in HSCs from control rats, HSCs from ethanol-fed rats, and primary rat hepatocytes. Inset, western blot analysis of $\alpha$-SMA expression in HSCs from either control or ethanol-fed rats. Western blots and cell survival assays are representative of $n=$ three independent experiments

Figure $2 \mathrm{CBD}$ induces ER dilation and expression of ER stress markers. (a) Activated rat HSCs were incubated for $6 \mathrm{~h}$ in serum-free media with $5 \mu \mathrm{M} C B D$ in the presence or absence of either $1 \mu \mathrm{M}$ AM251 or $1 \mu \mathrm{M}$ AM630. Cell lysates were subjected to western blot analysis and probed for cleaved PARP to detect cell death. ${ }^{* \star} P<0.01$ versus control (Student's $t$-test). Representative of $n=$ three independent experiments. (b) Cell viability of activated rat HSCs treated with $5 \mu \mathrm{M}$ CBD in the presence or absence of $1 \mu \mathrm{M}$ AM251 or $1 \mu \mathrm{M}$ AM630 was determined using the acid phosphatase assay as described in Materials and Methods. (c) Vehicle- or $5 \mu \mathrm{M}$ CBD-treated activated rat HSCs were visualized by light microscopy at $20 \times$ magnification after 4-h treatment. (d) Immunofluorescent staining of calnexin (green) in activated rat HSCs. Activated HSCs were incubated in serum-free media with either vehicle or $5 \mu \mathrm{M} \mathrm{CBD}$ for the indicated time periods. The cells were fixed and processed for immunostaining as described in Materials and Methods. Nuclei were stained with DAPI (blue). Cells were visualized at $63 \times$ magnification by confocal microscopy. (e) Activated rat HSCs were incubated in serum-free media in the presence or absence of $5 \mu \mathrm{M} \mathrm{CBD}$ for $4 \mathrm{~h}$, then fixed and processed for electron microscopy. Cells were imaged at $12000 \times$ magnification. White arrows indicate the ER. (f) Activated rat HSCs were incubated in serum-free media for $0-24 \mathrm{~h}$ with indicated concentrations of CBD. Cell lysates were subjected to western blot analysis and probed for CHOP and calnexin. Representative of $n=$ three independent experiments 


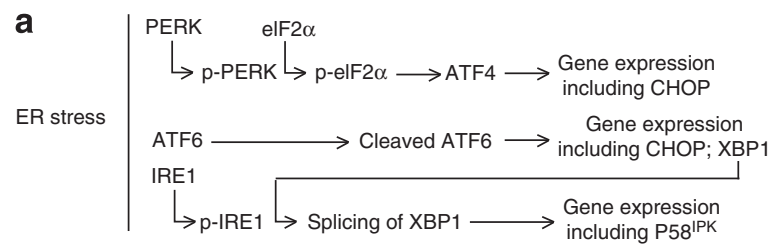

b
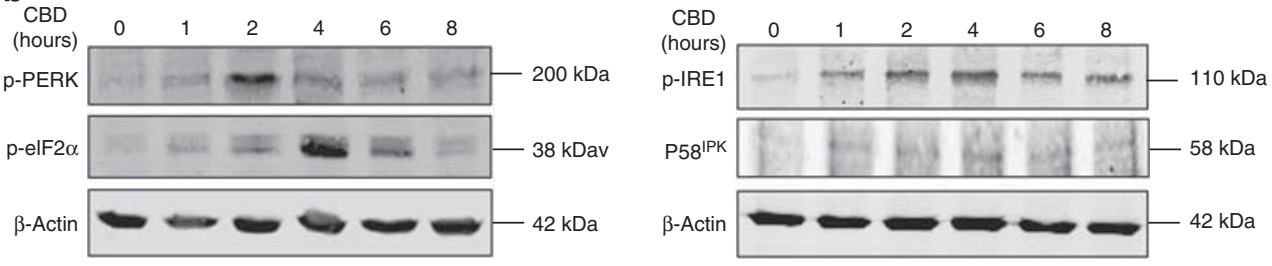

C
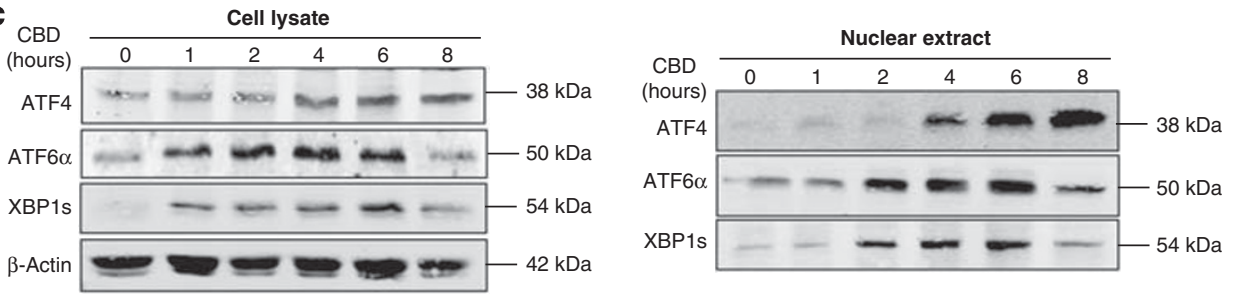

d

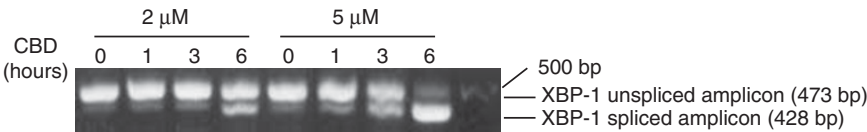

e
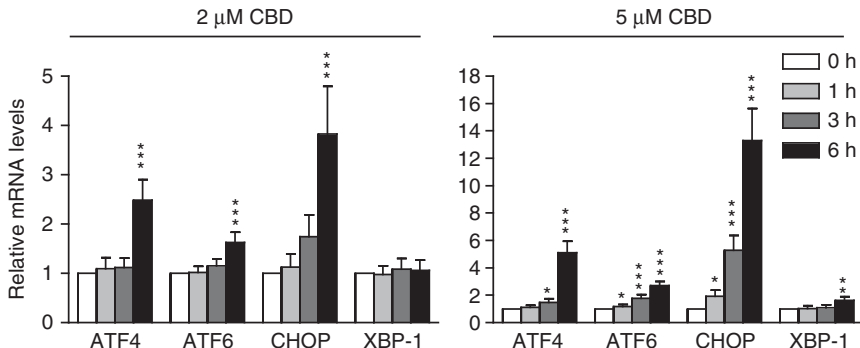

Figure 4 CBD induces ER stress response. (a) Schematic representation of the signaling pathways characterizing the ER stress response. In (b) through (e), activated rat HSCs were incubated in serum-free media with $5 \mu \mathrm{M} \mathrm{CBD}$, unless indicated otherwise, for the indicated time periods and processed for either (b and $\mathbf{c})$ western blot, (d) RT-PCR, or (e) qRT-PCR analysis of ER stress mediators. (b) Whole cell lysates were subjected to western blot analysis and probed for phospho-PERK, phospho-elF2 $\alpha$, phospho-IRE1, and P58 ${ }^{\mathrm{IPK}}$ to detect the PERK- and IRE1-mediated arms of the ER stress response. (c) Cell lysates and nuclear extracts were subjected to western blot analysis and probed for ATF4, cleaved ATF6 $\alpha$, and XBP1s to detect the presence of ER stress transcription factors in the nucleus. (d) Total RNA was extracted from cells and reverse transcribed to obtain cDNA used for PCR with primers specific for XBP1. Spliced XBP1 was detected by agarose gel electrophoresis. (e) Real-time RT-PCR was carried out with genespecific primers for ATF4, ATF6, CHOP, and XBP1 to detect relative mRNA levels at the indicated time points. Results are normalized to GAPDH, hypoxanthine-guanine phosphoribosyltransferase, and RNA polymerase II, and expressed as fold change over control \pm S.E.M. ( $n=$ three independent experiments in triplicate). ${ }^{*} P<0.05$; ${ }^{* \star} P<0.01 ;{ }^{\star \star \star} P<0.001$ versus control (Student's $t$-test)

Induction of the ER stress response by CBD was further confirmed by an increase in expression of the UPR genes ATF4, ATF6, CHOP, and XBP1. Although $2 \mu \mathrm{M}$ CBD treatment for $6 \mathrm{~h}$ induced significant increase in transcript levels of ATF4, ATF6, and CHOP, $5 \mu \mathrm{M}$ CBD led to even greater upregulation of these genes at earlier time points (Figure 4e).

Taken together, these results demonstrate that CBD treatment leads to the induction of all three signaling arms of the ER stress response in activated HSCs, resulting in significant upregulation of UPR genes and transcription factors. Along with our observation that CBD leads to apoptosis in activated HSCs, this provided strong evidence for ER stress as the underlying mechanism mediating the CBD-induced apoptotic response.

CBD promotes ER stress-induced apoptosis through activation of the IRE1/ASK1/JNK pathway in activated HSCs. In order to link the induction of ER stress to CBDmediated cell death, we examined signaling events downstream of the UPR that trigger apoptosis. IRE1 has been shown to be pro-apoptotic by activating apoptosis signal-regulating kinase 1 (ASK1) through dephosphorylation of its Ser967 residue. Activated ASK1 leads to 
a

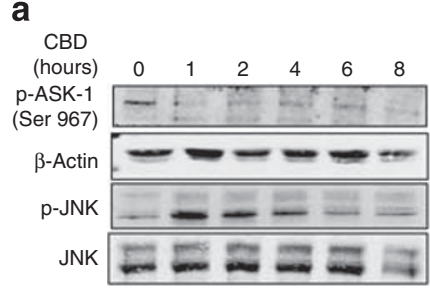

d
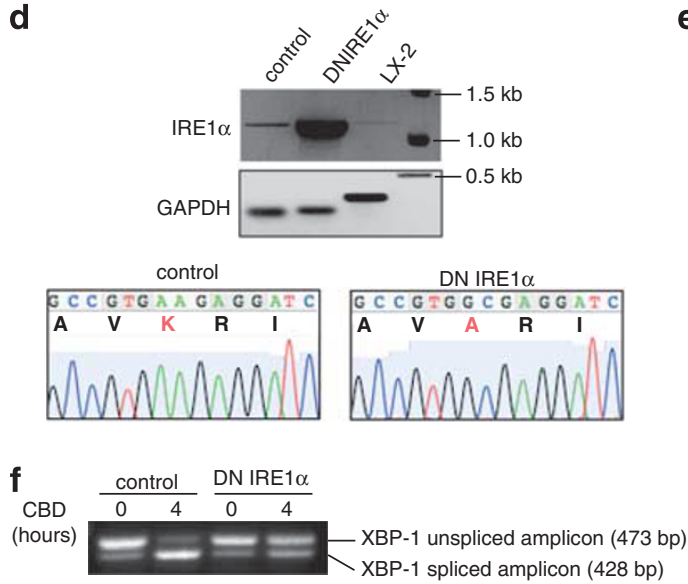

g

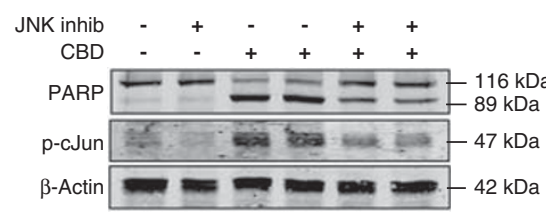

b

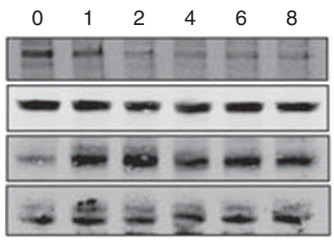

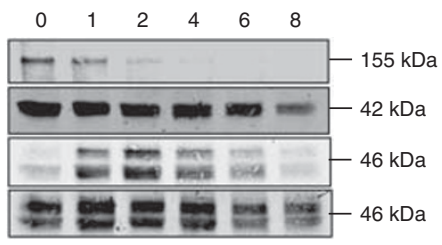

e
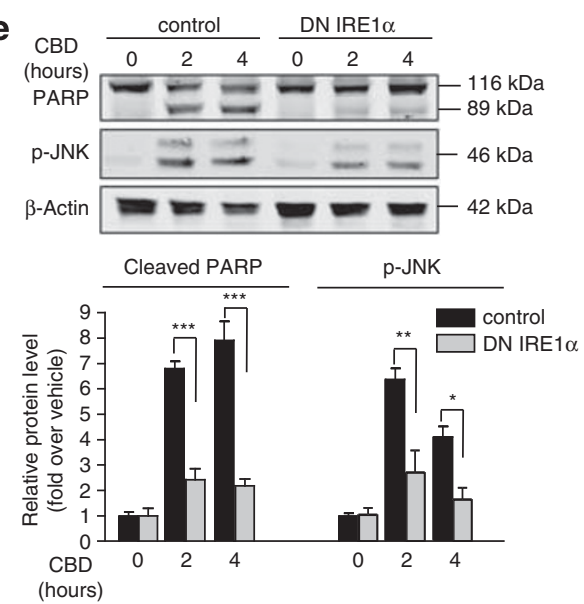

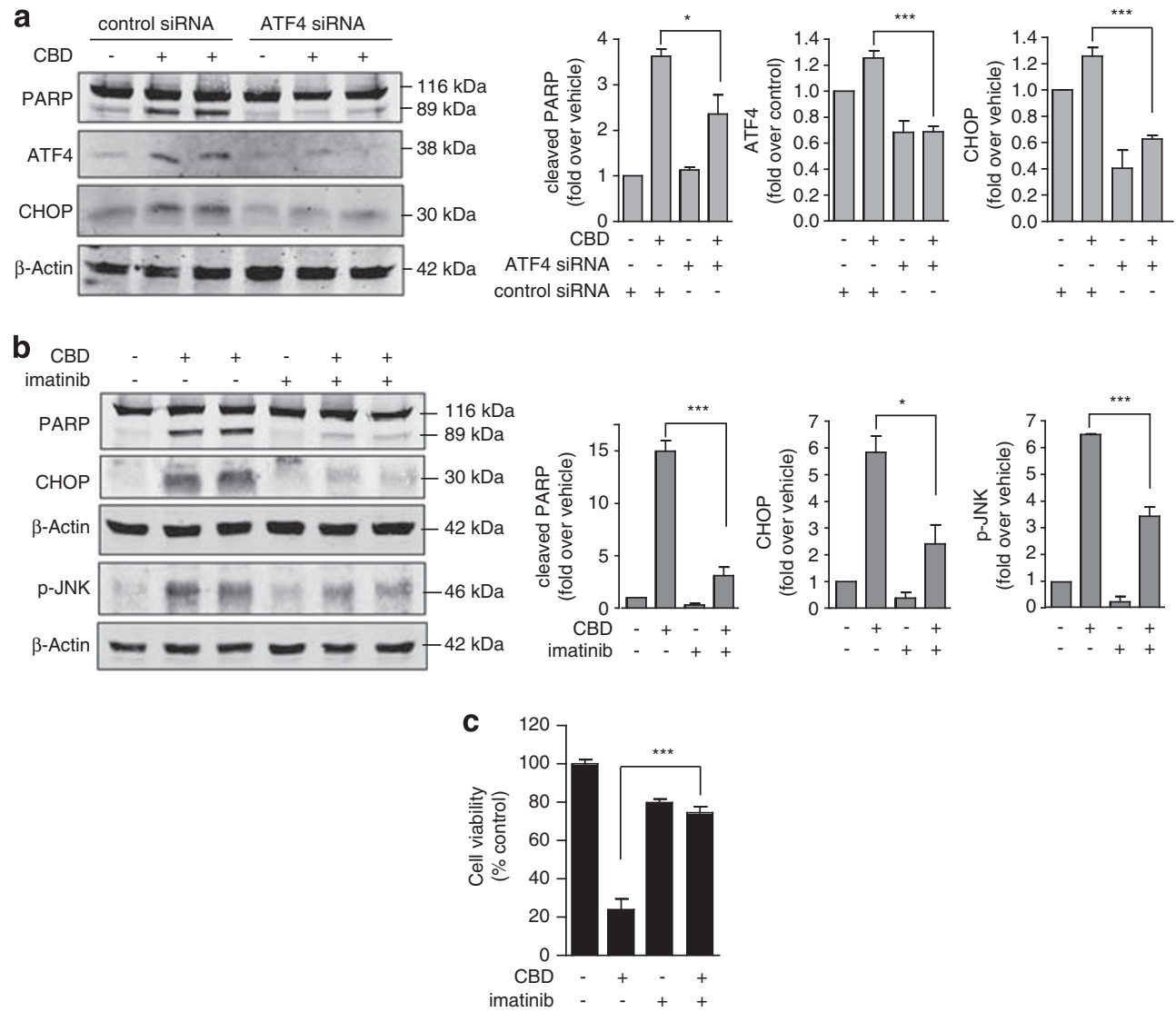

Figure 6 Inhibition of ER stress response protects against CBD-induced cell death. (a) JS1 cells were transfected with siRNA against ATF4. After $16 \mathrm{~h}$, cells were incubated with $5 \mu \mathrm{M} \mathrm{CBD}$ in serum-free media for $8 \mathrm{~h}$. Western blot analysis was used to determine PARP, ATF4, and CHOP expression, presented as fold over control \pm S.E.M. for $n=$ four independent experiments. (b) LX-2 cells were treated with $5 \mu \mathrm{M} \mathrm{CBD}$ in serum-free media for $8 \mathrm{~h}$ in the presence or absence of $10 \mu \mathrm{M}$ imatinib to inhibit ER stress. Expression of PARP, CHOP, and phospho-JNK was determined by western blot analysis and is presented as fold over vehicle \pm S.E.M. for $n=$ four independent experiments. (c) Acid phosphatase activity was used to measure LX-2 cell viability following treatment with CBD and imatinib as in (b). Cell viability is expressed as mean percent of control acid phosphatase activity \pm S.E.M. of triplicate experiments. ${ }^{* \star *} P<0.001 ;{ }^{* \star} P<0.05$

response in the pro-apoptotic effect of CBD. Using another approach to block the ER stress response, we treated LX-2 cells with $\mathrm{CBD}$ in the presence of imatinib, which has been shown to attenuate ER stress. ${ }^{21}$ Imatinib led to a significant decrease in CHOP induction, JNK phosphorylation, and PARP cleavage induced by CBD (Figure $6 \mathrm{~b}$ ), and protected against CBD-mediated activated HSC death (Figure 6c), providing strong evidence that $\mathrm{CBD}$ causes apoptosis by promoting ER stress.

Basal level of ER stress determines apoptotic effect of CBD. We then assessed the ER stress-mediated apoptotic effect of CBD by examining its action in the presence or absence of the ER stress inducer tunicamycin. We found that CBD and tunicamycin worked in synergy to increase LX-2 cell death in a dose-dependent manner (Figure 7a), supporting our finding that the apoptotic effect of $\mathrm{CBD}$ is mediated through an ER stress mechanism.

In order to further elucidate the role of CBD-induced ER stress as a mediator for apoptosis, we investigated the basis for specificity of this occurrence in activated HSCs. We first examined basal ER stress levels in activated versus control
HSCs and found that expression levels of the ER stress response genes ATF4, ATF6, and CHOP were increased in activated HSCs from ethanol-treated rats as compared to control HSCs from untreated rats (Figure $7 \mathrm{~b}$ ). This led us to hypothesize that the elevated basal ER stress level of activated HSCs rendered these cells more susceptible to the ER stress-mediated apoptotic effect of CBD. To test this, we treated control HSCs with tunicamycin and examined $\mathrm{CHOP}$ expression and PARP cleavage in the presence or absence of $\mathrm{CBD}$. Interestingly, we found that increasing the basal level of ER stress with tunicamycin in control HSCs led to an increase in CBD-induced CHOP expression and HSC death (Figure 7c). Taken together, this provided evidence that the increased basal level of ER stress in activated HSCs is an underlying factor, determining sensitivity to CBD and its induction of ER stress-mediated apoptosis.

\section{Discussion}

As the central effector of liver fibrosis, activated HSCs have been the focus of many studies examining mechanisms underlying the disease. The notion of activated HSCs as a target for the treatment of liver fibrosis ${ }^{22}$ has stimulated 
a

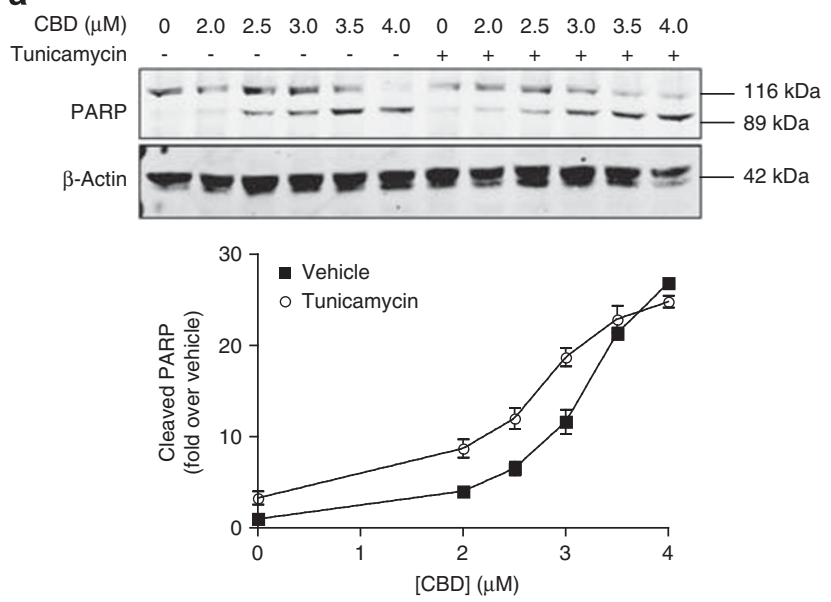

b

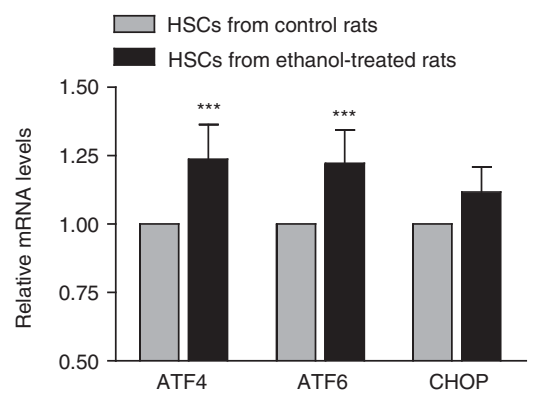

C

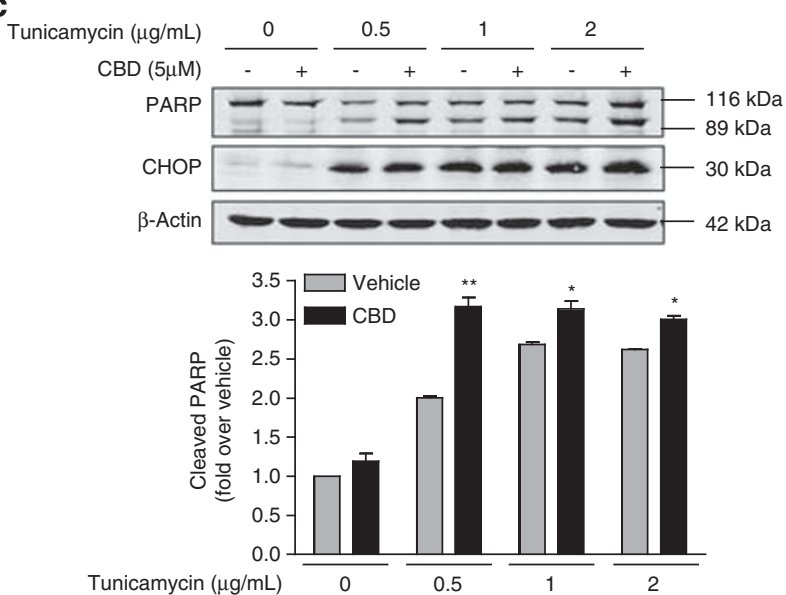

Figure 7 Basal ER stress determines sensitivity to CBD. (a) LX-2 cells were incubated in serum-free media with $0-4 \mu \mathrm{M}$ CBD for $6 \mathrm{~h}$ in the presence or absence of tunicamycin $(1 \mu \mathrm{g} / \mathrm{mL})$ to induce ER stress. Cell death was detected by western blot analysis of cleaved PARP, expressed as fold over vehicle \pm S.E.M. for $n=$ three independent experiments. (b) Total RNA was extracted from whole cell lysates of either ethanol-fed or control rat HSCs and reverse transcribed to cDNA. Real-time PCR was performed with gene-specific primers for ATF4, ATF6, and CHOP to determine the relative basal mRNA levels, normalized to GAPDH and expressed as fold over control. ${ }^{* * *} P<0.001$ (Student's $t$-test). (c) ER stress was induced in HSCs from control rats by incubation with the indicated concentrations of tunicamycin in the presence or absence of $5 \mu \mathrm{M} \mathrm{CBD}$ for $6 \mathrm{~h}$ in serum-free media. Cell death and ER stress were detected by western blot analysis of PARP and CHOP expression, respectively. Cleaved PARP is expressed as fold over control \pm S.E.M. for $n=$ three independent experiments. ${ }^{\star} P<0.05$; ${ }^{* *} P<0.01$ investigation of pathways that promote HSC apoptosis, proposed as a means to facilitate disease regression. ${ }^{23}$ Although a few antifibrotic agents have been identified thus far, including gliotoxin, ${ }^{24}$ sulfasalazine, ${ }^{25}$ and tectorigenin, ${ }^{26}$ these compounds often lack cell-type specificity in targeting activated HSCs. ${ }^{27,28}$

Recently, the endocannabinoid system has been established as a critical mediator of HSC activation and liver fibrosis, ${ }^{29}$ and studies with various cannabinoid ligands have demonstrated the therapeutic potential of this class of molecules. ${ }^{30}$ Interestingly, the phytocannabinoid CBD has been found to lead to death of proliferative cells, such as cancer cells and activated lymphocytes, through a variety of processes involving either cannabinoid receptor-dependent or -independent mechanisms. ${ }^{31}$ The proliferative nature of activated HSCs prompted us to examine the effect of CBD on these cells.

Remarkably, we found that $\mathrm{CBD}$ induced death of activated HSCs through apoptosis, an event that occurs independently of cannabinoid receptors. This led us to investigate alternative mechanisms for the pro-apoptotic effect of CBD. Alteration of ER morphology, evidenced by changes in calnexin distribution and ER dilation, suggested that CBD induces ER stress. This was confirmed by activation of PERK, ATF6, and IRE1, the three major mediators of the ER stress response, as well as their downstream signaling cascades. Induction of $\mathrm{CHOP}$, indicative of prolonged ER stress and pro-apoptotic signaling, further supported a CBD-induced ER stress response linked to apoptosis. The downstream activation of the pro-apoptotic ASK1/JNK cascade, known to be activated upon severe ER stress, as well as our findings that expression of DN IRE $1 \alpha$ and inhibition of JNK both markedly suppressed the apoptotic effect of CBD, provided evidence that CBD causes ASK1/ JNK-induced apoptosis in activated HSCs through an ER stress-mediated mechanism.

Importantly, the apoptotic effect of CBD was specific to the activated HSCs and could be seen in an activated HSC line derived from ethanol-fed rats, in human LX-2 cells, as well as in primary in vivo-activated HSCs from mouse. In contrast, this effect was absent in primary rat hepatocytes and was detectable in control HSCs only upon treatment with higher concentrations of CBD.

As HSCs are the major fibrogenic cells in the liver, their production and secretion of excess ECM proteins is dependent upon proper functioning of the ER. More so than in nonproliferative or non-fibrogenic cell types, the ER of activated HSCs undergoes stress during excessive collagen production, and maintaining homeostasis is likely aided by an adaptive basal ER stress response. We find that activated HSCs have a higher basal level of ER stress, supported by an upregulation of ATF4, ATF6, and CHOP mRNA expression in activated HSCs (responsive to CBD) as compared with control HSCs (not responsive to CBD). This could account for the selectivity of the pro-apoptotic effect of CBD in activated HSCs, wherein CBD exacerbates the pre-existing ER stress response, thereby switching signaling from adaptive to apoptotic. In line with this, inducing ER stress in control HSCs with tunicamycin led to a sensitization of these cells to CBD. Moreover, downregulation of ATF4 in untreated activated HSCs led to decreased CHOP expression and 
apoptosis, suggesting that blocking the basal level PERKmediated ER stress response reduces sensitivity to CBD, and that ER stress determines susceptibility to the pro-apoptotic effect of CBD. These observations offer insight into ER stress as a new intracellular pathway that could be targeted to achieve antifibrotic effects through selective elimination of activated HSCs.

Although ER stress has been linked to many pathophysiological processes, ${ }^{15}$ our studies show for the first time that it may be involved in the activated HSC phenotype, and that ER stress can be exploited in the context of hepatic fibrosis to kill specifically the HSCs that promote fibrosis. Our finding that CBD leads to activated HSC death independently of cannabinoid receptors further underscores the novelty of the mechanism proposed herein, in contrast to conventional cannabinoid ligands that mediate antifibrotic effects through their cognate receptors. ${ }^{30}$ Interestingly, other cannabinoid ligands such as delta-9-tetrahydrocannabinol have been shown to induce apoptosis in different cancer models such as glioma cells and pancreatic tumor cells through a mechanism involving ER stress, ${ }^{32,33}$ dependent on cannabinoid receptor activation. This is reminiscent of the proapoptotic effect of the $\mathrm{CB}_{2} \mathrm{R}$-dependent CP55940-induced HSC death that we observed, and suggests that CBD promotes ER stress-induced apoptosis in activated HSCs through a mechanism distinct from that of cannabinoid receptor agonists.

In this study, we find that CBD selectively kills activated HSCs through the previously unexplored mechanism of ER stress. We provide a molecular basis of action for CBD and identify CBD as a novel potential therapeutic agent for liver fibrosis. These promising findings warrant future investigation evaluating the antifibrotic effect of CBD in vivo. The prospect of $\mathrm{CBD}$ as a new antifibrotic compound is rendered more appealing by the fact that $C B D$ is a non-psychoactive small drug-like molecule already approved for clinical use in many countries.

\begin{abstract}
Materials and Methods
Materials. The following primary antibodies were used in this study: rabbit monoclonal anti-phospho-JNK, rabbit polyclonal anti-JNK, anti-PARP, anti-P58IKP, anti-eIF2 $\alpha$, anti-phospho-PERK, mouse monoclonal anti-CHOP (Cell Signaling Technology, Danvers, MA, USA), polyclonal anti-calnexin, monoclonal anti- $\beta$-actin (Sigma, St. Louis, MO, USA), rabbit polyclonal anti-ATF4, anti-ATF6, anti-XBP1, anti-pASK1, phospho-c-Jun, anti-CHOP (Santa Cruz Biotechnology, Santa Cruz, CA, USA), monoclonal anti- $\alpha$-SMA (Abcam, Cambridge, MA, USA), and polyclonal anti-phospho-IRE1 (Novus Biological, Littleton, CO, USA). The following secondary antibodies were used in this study: IRDye 680-labeled anti-rabbit, and IRDye 800labeled anti-mouse and anti-goat (Rockland Immunochemicals, Gilbertsville, PA, USA). The following compounds were used in this study: CBD, AM630, JWH133, PF514273, AM251, ACEA, AEA, 2-AG, CP55940, tunicamycin (Tocris Bioscience, Ellisville, MO, USA), JNK inhibitor 2 (Calbiochem, Gibbstown, NJ, USA), imatinib (Selleck Chemicals, Houston, TX, USA), and bis(p-nitrophenyl) phosphate (Sigma).
\end{abstract}

Cell culture. HSCs were maintained in DMEM/F12 50\% v/v + 10\% FBS. LX-2 cells ${ }^{14}$ were a gift from Dr. Scott Friedman. HSCs from ethanol-treated and control rats ${ }^{13,34}$ were a gift from Dr. Natalia Nieto. JS1 cells (mouse activated HSCs) and primary $\mathrm{HSCs}$ from mice that were chronically administered $\mathrm{CCl}_{4}$ for 1 month were a gift from Drs. Scott Friedman, Virginia Hernandez-Gea and Zahra Ghiassi-Nejad. Primary rat hepatocytes were obtained from Invitrogen (Carlsbad, CA, USA) and maintained according to manufacturer's protocol.
Cell viability assay. Cell viability was determined using an acid phosphatase assay as described. ${ }^{35}$ Briefly, cells were treated with vehicle (DMSO), CBD, or the indicated ligands and drugs for indicated times, then washed with PBS. $10 \mathrm{mM}$ bis(p-nitrophenyl) phosphate (substrate) in $165 \mathrm{mM} \mathrm{Na}$ acetate buffer, pH 5.5, containing $0.1 \%$ Triton $\mathrm{X}-100$, was added to cells and incubated at room temperature for $16-24 \mathrm{~h}$. Reaction was terminated by adding $1 \mathrm{~N} \mathrm{NaOH}$, and the absorbance at $410 \mathrm{nM}$ was measured using a spectrophotometer to determine acid phosphatase activity.

Western blot. Western blot analysis was carried out as described. ${ }^{36}$ Briefly, cells starved for $16 \mathrm{~h}$ were treated with $\mathrm{CBD}$ or with the indicated compounds. Cells were lysed in RIPA buffer and lysates were subjected to western blot analysis and probed for the indicated proteins using specific antibodies, according to manufacturer's protocols. Both blotting and imaging with the Odyssey imaging system (LI-COR, Lincoln, NE, USA) were performed following the manufacturer's protocols.

Flow cytometry. Cells were treated with vehicle or CBD for indicated times, and stained with FITC-AnnexinV and propidium iodide (BD Biosciences, San Jose, CA, USA), according to manufacturer's protocol. Flow cytometric analyses were performed on a three-laser LSRII with DiVa software (BD Biosciences). Data were analyzed with FlowJo software (Tree Star Inc., Ashland, OR, USA).

Electron microscopy. Cells were fixed with $3 \%$ glutaraldehyde, $\mathrm{pH} 7.4$. The specimens were then treated with $1 \%$ osmium tetroxide in $0.2 \mathrm{M}$ sodium cacodylate for $1 \mathrm{~h}$, followed by ethanol dehydration in graded steps through propylene oxide, and then embedded in Embed 812 (Electron Microscopy Sciences, Hatfield, PA, USA). Images were acquired on a Hitachi H7000 transmission electron microscope (Hitachi, Tokyo, Japan).

Immunofluorescence and confocal microscopy. This was carried out as described. ${ }^{36}$ Slides were visualized with a Leica TCS SP5 confocal microscope (Leica Microsystems, Heidelberg, Germany). Images were acquired with an x63/ 1.32 PL APO objective lens (Leica Microsystems) and analyzed in sequential scanning mode.

Reverse transcription-polymerase chain reaction (RT-PCR). Cells were treated with vehicle (DMSO) or CBD for indicated times, then washed with PBS. Total RNA was isolated using the RNeasy Mini Kit (QIAGEN, Valencia, CA, USA) and reverse transcribed using the High Capacity RNA-to-cDNA Kit (Applied Biosystems, Carlsbad, CA, USA). CDNA from activated HSCs was subjected either to standard PCR with Taq Polymerase (Invitrogen) to detect splicing, or to real-time PCR with SYBR Green (Applied Biosystems) to detect relative mRNA levels. For spliced Xbp1 detection by standard PCR, $500 \mathrm{nM}$ of each rat Xbp1-specific primers, ${ }^{37}$ sense $5^{\prime}$-AAACAGAGTAGCAGCACAGACTGC- $3^{\prime}$ and antisense $5^{\prime}$-TCCTTCTGGGTAGACCTCTGGGAG-3' were used with the following program: (1) $94^{\circ} \mathrm{C}$ for $4 \mathrm{~min}$, (2) 35 cycles of $94^{\circ} \mathrm{C}$ for $45 \mathrm{~s}, 63^{\circ} \mathrm{C}$ for $30 \mathrm{~s}$, and $72^{\circ} \mathrm{C}$ for $30 \mathrm{~s}$, and (3) $72^{\circ} \mathrm{C}$ for $10 \mathrm{~min}$. PCR products were separated by agarose gel electrophoresis to resolve the $473 \mathrm{bp}$ (unspliced) and $428 \mathrm{bp}$ (spliced) amplicons. Realtime PCR was performed using the following primers $(500 \mathrm{nM})$ for rat: ATF4 sense $5^{\prime}-\mathrm{T}$ ATGGATGGGTTGGTCAGTG-3' and antisense $5^{\prime}$-CTCATCTGGCATGGTTTCC- $3^{\prime}$; ATF6 sense $5^{\prime}$-GATTTGATGCCTTGGGAGTC- $3^{\prime}$ and antisense $5^{\prime}$-GGACCGA GGAGAAGAGACAG-3'; CHOP sense $5^{\prime}$-CCACACCTGAAAGCAGAAAC- $3^{\prime}$ and antisense $5^{\prime}$-CACTGTCTCAAAGGCGAAAG-3'; XBP1 sense $5^{\prime}$-GATGAATGCCCT GGTTACTG-3' and antisense 5'-AGATGTTCTGGGGAGGTGAC-3'; glyceraldehyde 3-phosphate dehydrogenase (GAPDH) sense 5'-TCAAGAAGGTGGTGAAGCAG-3' and antisense $5^{\prime}$-AGGTGGAAGAATGGGAGTTG-3'; RNA polymerase II sense $5^{\prime}$-G AAGATCGGGAAGTGCTCAG-3' and antisense $5^{\prime}$-ATCCGCAGAAGGTTACAAG G-3'; hypoxanthine-guanine phosphoribosyltransferase sense $5^{\prime}$-CCCAAATGGTT AAGGTTGC- $3^{\prime}$ and antisense $5^{\prime}$-TCAAGGGCATATCCAACAAC- $3^{\prime}$. Quantitative analysis was performed using the $\triangle \Delta \mathrm{C}_{\mathrm{T}}$ method and REST software (http:// www.gene-quantification.de). ${ }^{38}$

DN IRE1 $\alpha$ transfection. JS1 cells (mouse activated HSCs) were transfected with Addgene plasmid 20745 (Addgene, Cambridge, MA, USA) coding DN IRE1 $\alpha$ (K599A, dominant negative kinase mutant), generated by Dr. Fumihiko Urano, ${ }^{39}$ using Lipofectamine (Invitrogen). Stable lines were established by puromycin selection and clonal growth of resistant cells. Similar results were observed with three different clones. DN IRE1 $\alpha$ expression was verified by RT-PCR using the 
human/mouse IRE1-specific primers, sense 5'-CTCTATGCCTCTCCCTCAATG-3' and antisense $5^{\prime}$-AAGTCCTTCTGCTCCACATACTC- $3^{\prime}$ (spanning the mutation site), in JS1 wild-type cells, JS1 cells expressing DN IRE1 $\alpha$, and LX-2 cells, according to the RT-PCR methods as described above. PCR products were analyzed and purified by agarose gel electrophoresis, then sequenced using the IRE1 antisense primer. GAPDH-specific primers for either human (sense $5^{\prime}-G$ AAGGTGAAGGTCGGAGTC- $3^{\prime}$, antisense $5^{\prime}$-GAAGATGGTGATGGGATTTC- ${ }^{\prime}$ ) or mouse (sense $5^{\prime}$-TGAAGGTCGGTGTGAACG-3', antisense $5^{\prime}$-CAATCTCC ACTTTGCCACTG-3') were used in parallel as internal controls.

siATF4 transfection. JS1 cells in six-well plates were transfected with Stealth RNAi siRNA to ATF4 (Invitrogen) for $6 \mathrm{~h}$ using Lipofectamine (Invitrogen). Following transfection, cells were serum-starved for $16 \mathrm{~h}$, and then treated with CBD for the indicated times.

Statistical analyses. Statistical significance and $P$-values were determined by the Student's t-test when comparing two groups, or by one-way ANOVA with Bonferroni post test when comparing multiple groups, using the GraphPad Prism software (GraphPad Software, San Diego, CA, USA). P-value $\left({ }^{*} P<0.05\right.$; $\left.{ }^{\star *} P<0.01 ;{ }^{* \star *} P<0.001\right)$ of $<0.05$ was considered statistically significant.

\section{Conflict of Interest}

The authors declare no conflict of interest.

Acknowledgements. We thank $\mathrm{Dr}$. Scott Friedman for constructive discussions, comments, and the gift of the LX-2 cells, Drs. Virginia HernandezGea and Zahra Ghiassi-Nejad for the primary mouse HSCs and JS1 cells, Dr. Natalia Nieto for the rat HSCs, and Dr. Serine Avagyan for assistance with flow cytometry. This work was supported by NIH grants DA08863, DA019521 to LAD, AA017067 to RR, and R24 CA095823 to MSSM-Microscopy Shared Resource Facility.

1. Schuppan D, Afdhal NH. Liver cirrhosis. Lancet 2008; 371: 838-851.

2. Friedman SL. Mechanisms of disease: mechanisms of hepatic fibrosis and therapeutic implications. Nat Clin Pract Gastroenterol Hepatol 2004; 1: 98-105.

3. Friedman SL. Hepatic stellate cells: protean, multifunctional, and enigmatic cells of the liver. Physiol Rev 2008; 88: 125-172.

4. Friedman SL, Bansal MB. Reversal of hepatic fibrosis - fact or fantasy? Hepatology 2006 43: S82-S88.

5. Tam J, Liu J, Mukhopadhyay B, Cinar R, Godlewski G, Kunos G. Endocannabinoids in liver disease. Hepatology 2011; 53: 346-355.

6. Siegmund SV, Uchinami H, Osawa Y, Brenner DA, Schwabe RF. Anandamide induces necrosis in primary hepatic stellate cells. Hepatology 2005; 41: 1085-1095.

7. Malfait AM, Gallily R, Sumariwalla PF, Malik AS, Andreakos E, Mechoulam R et al. The nonpsychoactive cannabis constituent cannabidiol is an oral anti-arthritic therapeutic in murine collagen-induced arthritis. Proc Natl Acad Sci USA 2000; 97: 9561-9566.

8. Weiss L, Zeira M, Reich S, Har-Noy M, Mechoulam R, Slavin S et al. Cannabidiol lowers incidence of diabetes in non-obese diabetic mice. Autoimmunity 2006; 39: 143-151.

9. Hampson AJ, Grimaldi M, Axelrod J, Wink D. Cannabidiol and (-)Delta9tetrahydrocannabinol are neuroprotective antioxidants. Proc Natl Acad Sci USA 1998; 95: 8268-8273.

10. Ligresti A, Moriello AS, Starowicz K, Matias I, Pisanti S, De Petrocellis L et al. Antitumor activity of plant cannabinoids with emphasis on the effect of cannabidiol on human breast carcinoma. J Pharmacol Exp Ther 2006; 318: 1375-1387.

11. McAllister SD, Christian RT, Horowitz MP, Garcia A, Desprez PY. Cannabidiol as a nove inhibitor of Id-1 gene expression in aggressive breast cancer cells. Mol Cancer Ther 2007; 6: 2921-2927.

12. Vaccani $A$, Massi $P$, Colombo A, Rubino T, Parolaro D. Cannabidiol inhibits human glioma cell migration through a cannabinoid receptor-independent mechanism. Br J Pharmacol 2005; 144: 1032-1036.

13. Cubero FJ, Nieto N. Ethanol and arachidonic acid synergize to activate Kupffer cells and modulate the fibrogenic response via tumor necrosis factor alpha, reduced glutathione, and transforming growth factor beta-dependent mechanisms. Hepatology 2008; 48 2027-2039.

14. Xu L, Hui AY, Albanis E, Arthur MJ, O'Byrne SM, Blaner WS et al. Human hepatic stellate cell lines, LX-1 and LX-2: new tools for analysis of hepatic fibrosis. Gut 2005; 54: 142-151.

15. Kim I, Xu W, Reed JC. Cell death and endoplasmic reticulum stress: disease relevance and therapeutic opportunities. Nat Rev Drug Discov 2008; 7: 1013-1030.

16. Szegezdi E, Logue SE, Gorman AM, Samali A. Mediators of endoplasmic reticulum stressinduced apoptosis. EMBO Rep 2006; 7: 880-885.

17. Yan W, Frank CL, Korth MJ, Sopher BL, Novoa I, Ron D et al. Control of PERK elF2alpha kinase activity by the endoplasmic reticulum stress-induced molecular chaperone P58IPK. Proc Natl Acad Sci USA 2002; 99: 15920-15925.

18. Urano F, Wang X, Bertolotti A, Zhang Y, Chung P, Harding HP et al. Coupling of stress in the ER to activation of JNK protein kinases by transmembrane protein kinase IRE1. Science 2000; 287: 664-666.

19. Nishitoh H, Matsuzawa A, Tobiume K, Saegusa K, Takeda K, Inoue K et al. ASK1 is essential for endoplasmic reticulum stress-induced neuronal cell death triggered by expanded polyglutamine repeats. Genes Dev 2002; 16: 1345-1355.

20. Yang W, Tiffany-Castiglioni E, Koh HC, Son IH. Paraquat activates the IRE1/ASK1/JNK cascade associated with apoptosis in human neuroblastoma SH-SY5Y cells. Toxicol Lett 2009; 191: 203-210.

21. Han MS, Chung KW, Cheon HG, Rhee SD, Yoon CH, Lee MK et al. Imatinib mesylate reduces endoplasmic reticulum stress and induces remission of diabetes in $\mathrm{db} / \mathrm{db}$ mice. Diabetes 2009; 58: 329-336.

22. Bataller R, Brenner DA. Hepatic stellate cells as a target for the treatment of liver fibrosis. Semin Liver Dis 2001; 21: 437-451.

23. Iredale JP, Benyon RC, Pickering J, McCullen M, Northrop M, Pawley S et al. Mechanisms of spontaneous resolution of rat liver fibrosis. Hepatic stellate cell apoptosis and reduced hepatic expression of metalloproteinase inhibitors. J Clin Invest 1998; 102: 538-549.

24. Wright MC, Issa R, Smart DE, Trim N, Murray Gl, Primrose JN et al. Gliotoxin stimulates the apoptosis of human and rat hepatic stellate cells and enhances the resolution of liver fibrosis in rats. Gastroenterology 2001; 121: 685-698.

25. Oakley F, Meso M, Iredale JP, Green K, Marek CJ, Zhou X et al. Inhibition of inhibitor of kappaB kinases stimulates hepatic stellate cell apoptosis and accelerated recovery from rat liver fibrosis. Gastroenterology 2005; 128: 108-120.

26. Wu JH, Wang YR, Huang WY, Tan RX. Anti-proliferative and pro-apoptotic effects of tectorigenin on hepatic stellate cells. World J Gastroenterol 16: 3911-3918.

27. Anselmi K, Stolz DB, Nalesnik M, Watkins SC, Kamath R, Gandhi CR. Gliotoxin causes apoptosis and necrosis of rat Kupffer cells in vitro and in vivo in the absence of oxidative stress: exacerbation by caspase and serine protease inhibition. J Hepatol 2007; 47 103-113

28. Hagens WI, Olinga P, Meijer DK, Groothuis GM, Beljaars L, Poelstra K. Gliotoxin nonselectively induces apoptosis in fibrotic and normal livers. Liver Int 2006; 26: 232-239.

29. Teixeira-Clerc F, Julien B, Grenard P, Tran Van Nhieu J, Deveaux V, Li L et al. $\mathrm{CB} 1$ cannabinoid receptor antagonism: a new strategy for the treatment of liver fibrosis. Nat Med 2006; 12: 671-676.

30. Mallat $A$, Lotersztain $S$. Cannabinoid receptors as therapeutic targets in the management of liver diseases. Drug News Perspect 2008; 21: 363-368.

31. Mechoulam R, Peters M, Murillo-Rodriguez E, Hanus LO. Cannabidiol - recent advances. Chem Biodivers 2007; 4: 1678-1692.

32. Carracedo A, Lorente M, Egia A, Blazquez C, Garcia S, Giroux V et al. The stressregulated protein p8 mediates cannabinoid-induced apoptosis of tumor cells. Cancer Cell 2006; 9: 301-312.

33. Carracedo A, Gironella M, Lorente M, Garcia S, Guzman M, Velasco G et al. Cannabinoids induce apoptosis of pancreatic tumor cells via endoplasmic reticulum stress-related genes. Cancer Res 2006; 66: 6748-6755.

34. Urtasun R, Cubero FJ, Vera M, Nieto N. Reactive nitrogen species switch on early extracellular matrix remodeling via induction of MMP1 and TNFalpha. Gastroenterology 2009; 136: 1410-1422, e1411-e1414.

35. Fricker AD, Rios C, Devi LA, Gomes I. Serotonin receptor activation leads to neurite outgrowth and neuronal survival. Brain Res Mol Brain Res 2005; 138: 228-235.

36. Rozenfeld R, Devi LA. Regulation of CB1 cannabinoid receptor trafficking by the adaptor protein AP-3. Faseb J 2008; 22: 2311-2322.

37. Calfon M, Zeng H, Urano F, Till JH, Hubbard SR, Harding HP et al. IRE1 couples endoplasmic reticulum load to secretory capacity by processing the XBP-1 mRNA. Nature 2002; 415: 92-96.

38. Pfaffl MW, Horgan GW, Dempfle L. Relative expression software tool (REST) for groupwise comparison and statistical analysis of relative expression results in real-time PCR. Nucleic Acids Res 2002; 30: e36.

39. Lipson KL, Ghosh R, Urano F. The role of IRE1alpha in the degradation of insulin mRNA in pancreatic beta-cells. PLoS One 2008; 3: e1648. published by Nature Publishing Group. This work is licensed under the Creative Commons Attribution-Noncommercial-No Derivative Works 3.0 Unported License. To view a copy of this license, visit http://creativecommons.org/licenses/by-nc-nd/3.0/ 